\title{
Development of Collaboration Model by Integrating Information and Communication Technology (ICT) Tools in Higher Education Institutions (HEI)
}

\author{
Noor Azliza Che Mat, Noor Maizura Mohamad Noor, and Rosmayati Mohemad
}

\begin{abstract}
Collaboration in Higher Education Institution (HEI) level may occur with purpose to improve academic performance of the institution, to improve network alignment and performance to public needs as well as to share their expertise with other academic institutions. Two types of collaboration can be created at tertiary institutions: collaboration among HEI and collaboration between HEI and industries or businesses. A study showed that collaboration in HEIs remains limited even though collaboration contributes to a great number of advantages. Selecting the right collaborators for collaboration however is time consuming as identifying a set of intangible criteria is a challenging process. The criteria may not be easy to quantify as they involve subjective judgment. Therefore this study investigated the possibility to integrate Information and Communication Technology (ICT) systems in helping institutions to select the best possible collaborators. This study employed mixed methods approach which begins with online survey to gather the ranking of partner selection criteria, followed by conducting interviews with institutions. As a result, the findings developed produce a collaboration model by integrating ICT tools in the partner selection process.
\end{abstract}

Index Terms-Collaborator selection, higher education institutions, information and communication technology (ICT) tools, inter-organizational collaborators.

\section{INTRODUCTION}

The intensity of competition in the current business environment is higher than in the past [1]. One of the on-going challenges in the competitive environment is the development and retention of expertise for organisations including Higher Education Institutions (HEI). The definition of collaboration according to [2] can be defined as institutions that choose to work together in achieving impossible aims if they work in isolation.

Declining student numbers, increasing monetary force as well as pressure to international competition reputation have increasingly contribute to the increasing number of collaboration in HEI [3]. Collaboration seems much more common in research engagement as well as administration which offers the greatest performance improvement and efficiencies. In order to adapt to this challenging environment, organisations including HEIs have to restructure the scope of

Manuscript received January 9, 2018; revised May 14, 2018. This work was supported by Soft ware Technology Research Group Universiti Malaysia Terengganu

The authors are with the School of Informatics and Applied Mathematics, Universiti Malaysia Terengganu, 21030, Kuala Nerus, Terengganu, Malaysia (e-mail: azliza@umt.edu.my, maizura@umt.edu.my, rosmayati@umt.edu.my). their business by improving their competencies in dealing with new business models, strategies, organisational and governance principles, processes and technological capabilities [4]. Collaboration among HEI has become a mainstream strategy due to the range of competitive advantages it offers. Collaboration in HEI can be classified into two: may involve HEIs only as well as HEI and businesses/industries. Collaboration contributes to several benefits to institutions as they can pool knowledge between collaborators for better outcomes as well as leverage the expertise of partners in entering new market segment. The term institution will be used in the remaining sections which refers to organisations and businesses involved in collaboration.

A framework for classifying institutional collaboration and consolidation provided by The Higher Education Finding Council for England (HEFCE) consists of a continuum of networks, collaborations, alliances and mergers [3], [5], [6] However, in this paper the classification of collaboration has been modified to suit the spectrum of collaboration provided by [7], [8].

TABLE I: SPECTRUM OF NETWORK-COORDINATION-COOPERATION-COLLABORATION ([9]-[11]

\begin{tabular}{llll}
\hline \hline Networking & Coordination & Cooperation & Collaboration \\
\hline Exchanging & Exchanging & Exchanging & Exchanging \\
information & information for & information, & information for \\
for mutual & mutual & altering & mutual benefit, \\
benefit & benefits, & activities, & altering activities, \\
& altering & sharing & sharing resources, \\
& activities for & resources for & enhancing capacity \\
& mutual benefit & mutual benefit & of one another for \\
& and to achieve & and to achieve & mutual benefit and \\
& a common & a common & to achieve a common \\
& purpose & purpose & purpose \\
\hline \hline
\end{tabular}

Collaboration is one of the strategy to keep the survival of small sized HEIs as they are able to pool resources and reduce risks. Commonly, collaboration is useful to strengthen institutional governance, professional management, create interdisciplinary synergies and to overcome financial oversight [3]. Collaboration may allow HEI to develop a joint programme of study in fulfilling the public needs.

Despite the benefits offered through collaboration, HEIs are still struggling in engaging with industries/businesses in solving problems [3]. The decision making process in selecting compatible partners in collaboration is one of the challenges for managers as the limitation of the availability of information regarding their partners.

Interestingly, the growth of ICT is offering new opportunities for collaboration environment. Consequently, 
it is significant to identify how ICT tools can help organization to make decisions, specifically in evaluating and accommodating information regarding partner selection criteria. Therefore, the motivation of this paper is to explore the following research questions 'What are the ICT tools that can be used to evaluate the intangible criteria' and 'How the ICT tools can be used to evaluate the criteria'.

The paper proceeds in the following manner. Section II presents the current issues related to partner selection. Meanwhile, the usage of ICT tools in helping institutions to make decisions about the right partner selection is detailing out in Section III. Section IV discusses the influence of ICT on inter-organizational collaboration. Research methodology is explained in Section V. Subsequently, results and findings are reported in Section VI and discussion is presented in Section VII. Finally, Section VIII concludes with a summary of this paper and future research directions.

\section{ISSUES IN PARTNER SELECTION}

[12] classified partner selection criteria into two categories: partner-related criteria, and task-related criteria. The focus of this study is on partner-related criteria or known as intangible criteria related to the behavioral aspects of working life such as trust, commitment or leadership. These criteria are difficult to be measured with numerical values and they can be freely interpreted. An extensive group of criteria have been listed in the previous research but it is important to choose the right partner at the early stage of collaboration [13]-[16] to help organizations form the collaboration as quickly as possible. Table II shows a number of partner selection criteria which have been identified by [17] from literature reviews related to partner-selection criteria. Several terms of these criteria however were renamed and reorganized in order to match the designated table.

TABLE II: PARTNER SELECTION CRITERIA

\begin{tabular}{ll}
\hline \hline Criteria & $\begin{array}{l}\text { Number of studies } \\
\text { related to the criteria }\end{array}$ \\
\hline Trust & 21 \\
Commitment & 10 \\
Similarity in objectives & 16 \\
Integrity & 9 \\
Contribution of complementary resources & 15 \\
Ability to learn/share the expertise/skill & 3 \\
Knowledge of local/host market & 4 \\
Record of pre-existing collaboration & 9 \\
Size & 10 \\
Management experience and attitude & 7 \\
Previous track record in collaborative projects & 7 \\
Previous track record in business & 15 \\
Experience in using technology application & 6 \\
Ability to negotiate with local/host government & 4 \\
Organizational cultural similarity & 8 \\
\hline \hline
\end{tabular}

According to a study conducted by [18] regarding the creation of effective engagement between universities and businesses with 80 participants from academia and industries shows that the highlighted challenges include lack of trust as well as uncertainty about the advantages of collaboration.

Another interesting issue in partner selection related to partner selection process is how to form a speedy and competent decision of selecting partners. In order to answer this question, an exploration about the possibility of ICT tools is considered as tools to help institutions in evaluating the partner selection criteria. Currently there is a gap in a study of ICT tools in using ICT to evaluate partner selection criteria.

\section{ICT TOOLS AND INTER-ORGANISATIONAL COLLABORATION}

ICT can be defined as any technology which includes products or services such as desktop computers, wired or wireless intranet, software, storage and security, and computer-mediated networks that incorporate technology and infrastructure that enable people to store, manipulate, deliver and transmit information [19]-[22].

TABLE III: ICT TOOLS (ADAPTED FROM [31], [32])

\begin{tabular}{|c|c|c|}
\hline System & Description & Example \\
\hline Communication & $\begin{array}{l}\text { Technologies that provide } \\
\text { and enable communication } \\
\text { between geographically } \\
\text { scattered people with low } \\
\text { cost, easy and fast }\end{array}$ & $\begin{array}{l}\text { Email, instant messaging, } \\
\text { SMS, message board, } \\
\text { phone, VOIP, } \\
\text { teleconference, Web } \\
\text { conferences }\end{array}$ \\
\hline $\begin{array}{l}\text { Information/ } \\
\text { knowledge } \\
\text { sharing }\end{array}$ & $\begin{array}{l}\text { Technologies that enable } \\
\text { large amounts of data to be } \\
\text { stored and retrieved } \\
\text { quickly, reliably and } \\
\text { cheaply }\end{array}$ & $\begin{array}{l}\text { Document repositories, } \\
\text { share points/intranet, } \\
\text { Wiki, social media tools, } \\
\text { newsletter/ mailing lists, } \\
\text { blogs, FTP, CRM, SAP, } \\
\text { network drives, } \\
\text { document/screen } \\
\text { applications for Web } \\
\text { conferences }\end{array}$ \\
\hline Coordination & $\begin{array}{l}\text { Technologies that facilitate } \\
\text { distributed teamwork with } \\
\text { synchroniser to integrate } \\
\text { the work processes of a } \\
\text { team }\end{array}$ & $\begin{array}{l}\text { Group calendar, } \\
\text { workflow management } \\
\text { system, project } \\
\text { management tools }\end{array}$ \\
\hline Cooperation & $\begin{array}{l}\text { Technologies that provide } \\
\text { document-sharing and } \\
\text { co-authoring facilities in } \\
\text { improving teamwork }\end{array}$ & Google Docs, Dropbox \\
\hline $\begin{array}{l}\text { Group } \\
\text { maintenance }\end{array}$ & $\begin{array}{l}\text { Technologies that enable } \\
\text { people to meet each other } \\
\text { between geographically } \\
\text { distributed teams }\end{array}$ & Virtual world, Skype \\
\hline
\end{tabular}

Many researchers and practitioners have advocated the use of ICT as a source of competitive advantage and have found that ICT has a significant impact on organisational performance [19], [23]-[27]. Moreover, it has been claimed that ICT is important for economic survival and growth [26].

The rapid development and improvement of the usage of ICT can be applied and implemented in various sectors such as education. ICT is also a strategic and tactical tool for organisations as it can bring great benefits to organisations at different levels (operational level, tactical level and strategic level) in promoting and strengthening competitiveness of organisations [28], [29]. ICT has proved its ability to help institutions to operate more efficiently and effectively and yet competitive [25]. Institutions can also exchange real-time information and create better relationships with existing customers, attract new customers and build closer connections with suppliers and business partners [30]. 
According to [31], ICT tools can be categorised based on the basic interaction or group processes that the tools support. The interaction process categories are based on a previous study related to effective teams: communication, information/knowledge sharing, co-operation, co-ordination and group-oriented processes [32]. These processes are used to classify the ICT tools according to the group of tools: 1) communication systems, 2) co-operation systems, 3) co-ordination systems (including workflow management systems), 4) information sharing and consulting systems, and 5) tools to support social encounters [33].

However, the present study adopted the modification of the categories as proposed by [32] by changing the fourth and fifth categories into "Information/Knowledge Sharing Systems" and "Group Maintenance Systems". The classification of ICT tools and examples of ICT tools for each group are shown in Table III.

\section{INFLUENCE OF ICT ON INTER-ORGANISATIONAL COLLABORATION}

ICT facilitates the interaction between organisations and consequently has entirely changed the models of relationship between organisations [34]. In order to benefit from the developments in ICT, organisations must come up with innovative means of establishing collaboration. The most vital advance made possible by ICT is the linking of organisations via technology [35]. Consequently, the growth of an Internet-based environment facilitates the transition from traditional collaboration to technology-based collaboration or digitally networked collaboration [28], [34]. Fig. 1 shows the transformation of organisations through levels of ICT influence in 1990s.

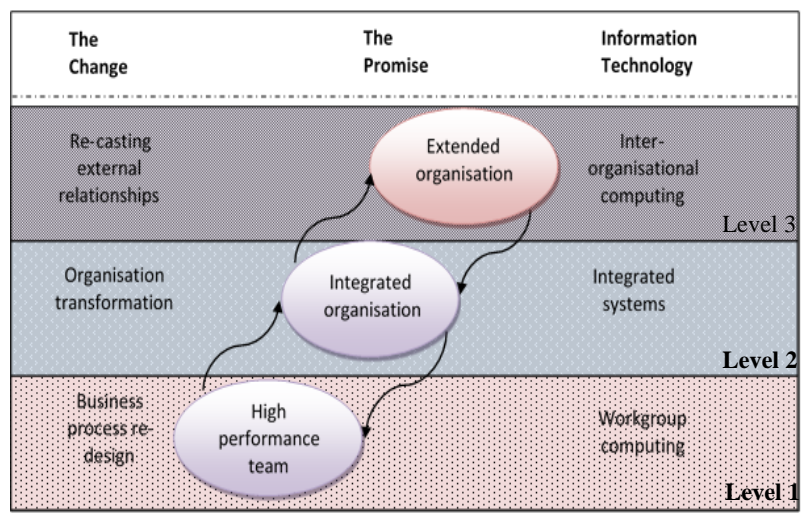

Fig 1. Transformation of organisations through three levels of ICT influence and competitive pressures in the 1990s [35].

As more and more organisations use computers to interact with each other and to perform business transactions, organisations consequently transform and restructure to create new working environments and corporate values (Level 2 in Fig. 1) [35]. Organisations move towards co-ordinated and integrated ICT infrastructure to achieve competitive advantage. Integrated systems support the integration of business processes and technology and at the same time enable flexibility and responsiveness to business priorities and change [36].

The emergence of extended organisations is the next step to follow integrated organisations (Level 3 in Fig. 1) [36].
Instead of working individually on complex services or processes, the manifestation of this paradigm is useful as it provides a combination of various types of organisations working together in one environment [36]. Nowadays, organisations are moving into collaborative networks (which also comprises extended organisations) in various areas such as in education, industry, services and research in response to business opportunities. Collaborative networks have utilised the advantages of ICT development and pervasive computing to enable and create a new dimension of organisational formation [37].

Collaborations supported by ICT have enormous implications for the operation, structure and strategy of the organisations by providing more opportunities to communicate, share and collaborate globally in geographically dispersed locations in order to achieve business goals [28], [38]. Moreover, ICT has also provided a new means of storing, processing, disseminating and exchanging information among organisations [39] and also helps organisations to interact more efficiently [28]. Empirical study has shown the effectiveness of ICT for supporting virtual teams in making decisions in various areas [40]-[42] The rapid growth of ICT has greatly assisted organisations in information dissemination and exchanges and has driven the development of the distributed digital environment [43].

In summary, ICT is an impetus for the development of technology-based collaboration between organisations such as collaborative networks as it provides a conducive and supportive environment for organisations to work together [44], [45]. Institutions that are unable to adopt ICT in their inter-organisational collaboration will not gain competitive advantages.

\section{ResearCh Methodology}

Mixed methods approach has been implemented in this study which begins with quantitative approach (online survey) followed by qualitative approach (interviews). Prior online survey and an extensive literature review was performed purposely to identify the criteria for selecting partners. A number of established journal papers and conferences were referred in order to gather the criteria which have been used in the previous studies. As a result, a list of criteria of partner selection were employed to design the online survey. The online survey is purposely done to gather the significant criteria for partner selection.

Due to the limitation of the online survey in providing detailed information regarding the criteria, interviews were conducted to the selected organisations to gain insight understanding regarding the partner selection criteria.

The main key people in the selected organisations were interviewed to obtain their experience and knowledge regarding the criteria. Moreover, they were also asked to give their opinions regarding the ICT tools to be integrated in their decision making.

\section{Results And FIndings}

The following discussion regarding the analysis of the 
result of quantitative and qualitative can be divided into two folds: quantitative and qualitative. For quantitative analysis, exploratory factor analysis (EFA) was employed to collect information on the interrelationship among variables. EFA was used to reduce the number of related variables to a more manageable set and to reduce the dimensionality of the critical success factors as an introduction to conduct further analysis. The quantitative findings help to provide the overall view from respondents which were then used to design the qualitative case studies. The findings from the online survey show that the partner selection criteria can be divided into three main factors: Attitude, Experience-Local Government and Track Record-Local Market. The first factor namely Attitude has high positive loading and consists of Trust, Commitment and Integrity. The second group namely Experience/Local Market has high positive loadings on the criteria 'Ability to negotiate with local/hosts government' and 'Management Experience and Attitude'. The third group known as History has high positive loading on criteria /Previous Track Record in Business' and Knowledge of the local host/market.

Due to the limitation of online survey which is not able to provide detailed information regarding the importance of each criterion, interview case studies were then conducted. The key people who have experience in selecting partners for collaboration were involved as participants for the next phase of the study.

Seven criteria identified in selecting partners have been examined in order to know the reasons of the importance of them. Moreover, the interviewees were also asked regarding the use of ICT in helping them in making decisions. Previous studies conducted by [17], [46] have identified the importance of each criterion in collaboration. Further discussion regarding the quantitative and qualitative results can be referred to studies conducted by [17], [46].

\section{DISCUSSION}

Fig. 2 shows the finding of this study by relating the ICT tool system as stated in Table III. The findings show that the most applicable system that can be used to evaluate the core criterion is 'Information/Knowledge Sharing' and Communication. In the level of cooperation, coordination and collaboration, it is possible for institutions to use all ICT system tools to evaluate the core criterion.

In the 'Information/Knowledge Sharing', the technologies allow a low-cost and efficient means for a large amount of data to be stored and assessed quickly and also reliable. The tools such as document repositories allow institutions to share their documents in a cloud-based manner with other partners in order to create trustworthiness as well as to prove their commitment in collaboration. Moreover, the tools in 'Information/Knowledge Sharing' provide a better environment for HEIs to evaluate the attitude and experience of their potential partners by using media social tools such as Facebook, Instagram or Tweeter to get information about their experience or comments about them. The tools also allow institutions to get a quick information or recommendations regarding their potential partners. Thus the HEIs could use this knowledge gauge to help them in evaluating the capability of their partner in terms of performing their responsibility.

Another ICT system is 'Communication' tools such as WhatsApp application, email, instant messaging, Short Messaging Service (SMS) or web conference, and Voice over Internet Protocol (VoIP) such as Skype. These tools provide and enable communication between geographically scattered institutions which are low cost and fast. For instance, WhatsApp is one of the fast-growing communication applications which help institutions to communicate with their future partners in identifying their commitment to the tasks given. WhatsApp is also an effective tool to support staff management in coordination and correcting distribution of information where managers between institutions can implement motivational strategies towards their team to help them clear their objectives. It allows quick feedback in monitoring and commenting as well as providing useful advice. Moreover, by optimizing this real-time communication, the management has a great opportunity to prove their commitment and good management experience and attitude by constantly updating the tasks given or on-going negotiations as well as to monitor results. In addition, the tools lead to a considerable saving of time and money.

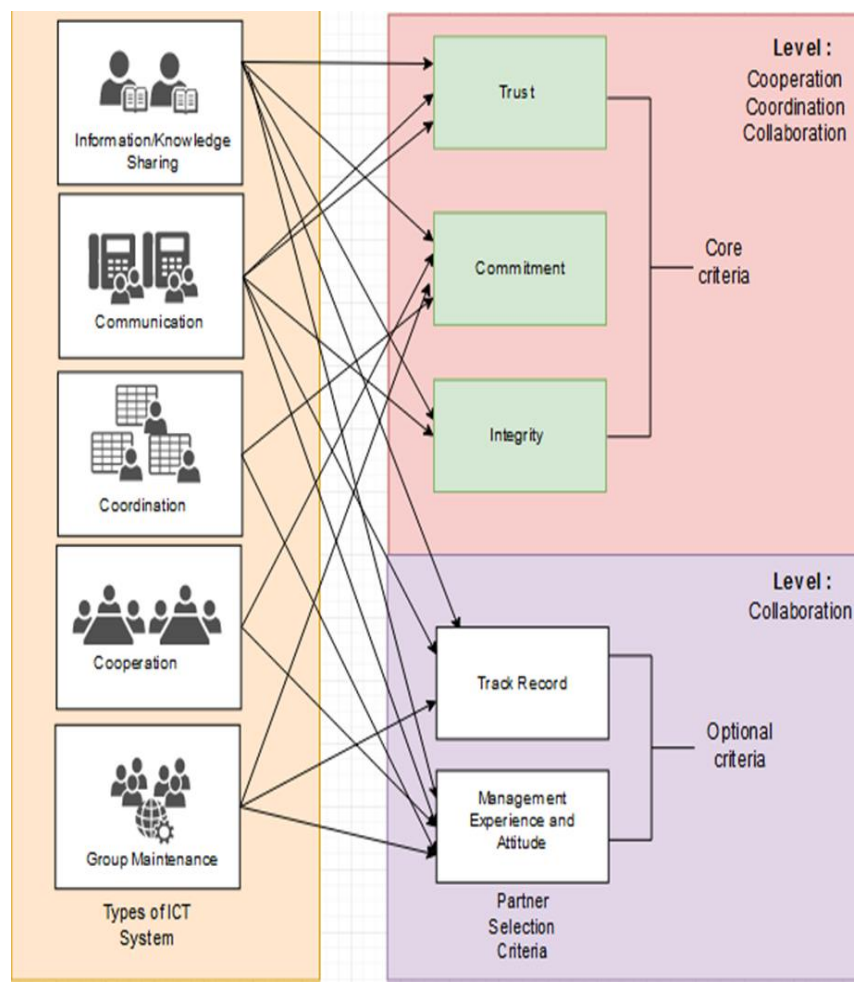

Fig. 2. A collaboration model by integrating ICT system.

Another ICT system that can be used to evaluate partner selection criteria is 'Coordination' and 'Cooperation' which helps institutions that are geographically scattered to work harmonically by integrating the tasks. Tools such as project management tools, and group calendar which is cloud-based allow them to synchronize their documents. For instance, one of the main functions of Google Calendar is to help institutions to manage appointments. Simultaneously, it also allows you to search and share the timeline with your team and potential partners. Furthermore, the use of Google Docs and Dropbox allows document sharing and co-authoring 
facilities in improving teamwork. Thus the tools allow the institutions to evaluate commitment and their potential management experience and attitude towards the assigned tasks.

For 'Group Maintenance', the tool such as Skype allows institutions to work virtually with low-cost expenses as it provides space for them to have an online meeting simultaneously with the partners who are based in various locations. Usually, this tool is a low-cost solution or the problem of communication with large number of partners in remote locations. In order to organise a virtual meeting, all parties should have their mutual agreement in identifying suitable schedule that can fit to every partner in the collaboration. Thus, this tool explicitly reveal the commitment of the involved parties in establishing collaboration. Moreover, this tools support varieties of communication in a form of text-based chat room, computer conference, graphical icons, virtual gestures or sound. By looking to this form of communication, it allow all parties to evaluate commitment of their partners.

\section{CONCLUSION AND FURTHER WORK}

In conclusion, a number of intangible criteria for selecting partners have been identified in this study. The criteria were then related to ICT system in order to evaluate the criteria. ICT system seems possible to be employed in evaluating the criteria as it provides tools that could help measure them. By integrating ICT tools such as WhatsApp, Skye or Facebook, it gives an advantage to HEI in the academic environment. Moreover, the popularity of social media helps the institutions to get rapid insight towards collaborative environment.

In the future, this study will explore the possibilities to integrate the designated model with decision support system (DSS) to help in evaluating the criteria for selecting partners in HEI. By integrating DSS in the partner selection process, the process of establishing collaboration seems like a promising way of improving efficiency.

\section{REFERENCES}

[1] T. M. Welbourne and M. Pardo-del-Val, "Relational capital: Strategic advantage for small and medium-size enterprises (SMEs) through negotiation and collaboration group decision and negotiation," 2008, vol. 18 , no. 5 , pp. 483-497.

[2] D. Lang, "There are mergers, and there are mergers: The forms of inter-institutional combination," Higher Education Management and Policy, 2002, vol. 14, no. 1, pp. 11-50.

[3] J. Williams, "Collaboration, alliance, and merger among higher education institutions," OECD Education Working Papers, 2017, p. 131.

[4] L. Camarinha-Matos, H. Afsarmanesh, and M. Ollus, "Methods and tools for collaborative networked organizations," New York, NY: Springer Science+Business Media, p. 528, 2008.

[5] HEFCE, "Collaborations, alliances and mergers in higher education: Lessons learned and guidance for institutions," Higher Education Funding Council for England, London, 2012, p. 21.

[6] B. E. E. T. Pruvot,and P. Mason, "Define thematic report: University mergers in Europe," European Universities Association, Brussels, 2015.

[7] L. M. Camarinha-Matos and H. Afsarmanesh, International Journal of Production Research, 2008, vol. 46, no. 9, p. 2453.

[8] L. M. Camarinha-Matos and A. Hamideh, "Collaborative Networks: Value creation in a knowledge society," presented at PROLAMAT
2006 IFIP International Conference on Knowledge Enterprise, 2006, Shanghai China: Springer.

[9] A. T. Himmelman, "On the theory and practice of transformational collaboration: From social service to social justice," Creating Collaborative Advantage, 1996, Sage Publications: London, pp. 19-43.

[10] A. T. Himmelman, "On coalitions and the transformation of power relations: Collaborative betterment and collaborative empowerment," American Journal ofCommunity Psychology, 2001, vol. 29, no. 2.

[11] V. J. McKendall, Factor Faciliting Interorganisational Collaboration, 1996, University of Minnesota.

[12] J. M. Geringer, "Strategic determinants of partner selection criteria in international joint ventures," Journal of International Business Studies, 1991, vol. 22, no. 1, pp. 41-61.

[13] F. Baldo, R. Rabelo, and R. Vallejos, "An ontology-based approach for selecting performance indicators for partners suggestion," Establishing the Foundation Of Collaborative Networks, 2007, Springer Boston, pp. 187-196.

[14] L. M. Camarinha-Matos et al., Establishing the Foundation of Collaborative Networks IFIP TC 5 Working Group 5.5 Eighth IFIP Working Conference on Virtual Enterprises, September 10-12, 2007, Guimaräaes, Portugal, 2007.

[15] L. Dong and K. W. Glaister, "Motives and partner selection criteria in international stategic alliances: Perspectives of Chinese firms," International Business Review, 2006, vol. 15, pp. 577-600.

[16] T. Jarimo, I. Salkari, and S. Bollhalter, "Partner selection with network interdependencies: An application," Network-Centric Collaboration and Supporting Frameworks, 2006, Springer Boston, pp. 389-396.

[17] N. A. C. Mat and Y. C. H. Scheepers, "Partner selection: Criteria for successful collaborative network," presented at Australasian Conference on Information Systems, 2009, Melbourne, Australia.

[18] S. Jones and S. Clulow, "How to foster a culture of collaboration between universities and industry," Higher Education Network Blog 2012.

[19] O. O. Adeosun, T. H. Adeosun, and I. A. Adetunde, "Strategic application of information and communication technology for effective service delivery in banking industry," Journal of Social Sciences, 2009, vol. 5, no. 1, pp. 47-51.

[20] R. Ashrafi and M. Murtaza, "Use and impact of ICT on SMEs in Oman,” Electronic Journal Information Systems Evaluation, 2008, vol. 11 , no. 3, pp. 125-138.

[21] I. Apulu and A. Latham, "Benefits of information and communication technology in small and medium sized enterprises: A case study of a Nigerian SME," in Proc. the 15th Annual Conference on UK Academy for Information Systems (UKAIS), 2010, Oriel College, University of Oxford.

[22] S. Wangwe, "A review of methodology for assessing ICT impact on development and economic transformation: Contribution to the AERC Project on the impact of ICTs on economic development and transformation," 2007.

[23] C. Chibelushi and E. Training, "Learning the hard way? Issues in the adoption of new technology in small technology oriented firms," 2008, vol. 50 , no. $8 / 9$, pp. $725-736$

[24] A. A. Erumban and S. B. Jong, "Cross-country differences in ICT adoption: A consequence of culture?" Journal of World Business, 2006, vol. 41 , no. 4 , pp. 302-314

[25] D. Fink and G. Disterer, "International case studies: to what extent is ICT infused into the operations of SMEs," Journal of Enterprise Information, 2006, vol. 19, pp. 608-624.

[26] H. M. C. M. Maldeni, and S. Jayasena, "Information and communication technology usage and bank branch performance," The International Journal on Advances in ICT for Emerging Regions, 2009, vol. 2 , no. 2 , pp. 29

[27] L. Obijiofor, S. Inayatullah, and T. Stevenson, "Impact of new information and communication technologies (ICTs) on the socio-economic and educational development of Africa and the Asia-Pacific region, in The third working conference on Information and Communications Technology solutions for government operations,e-government and national development," An African Regional WSIS PrepCom Pre-Event, Accra InternationalConference Centre2005: Accra, Ghana.

[28] D. Buhalis, "eAirlines: Strategic and tactical use of ICTs in the airline industry," Information and Management, vol. 41, 2003, pp. 805-825.

[29] P. E. D. Love, Z. Irani, and D. J. Edwards, "Industry-centric benchmarking of information technology benefits, costs and risks for small and medium sized enterprises in construction," Automation in Construction, 2004, vol. 13, no. 4, pp. 507-524.

[30] I. Apulu and A. Latham, "Drivers for information and communication technology adoption: A case study of Nigerian small and medium sized 
enterprises," International Journal of Business and Management, 2011, vol. 6 , no. 5 .

[31] J. H. E. Andriessen, "Working with groupware - Understanding and evaluating collaboration technology," Computer Supported Cooperative Work, 2003, p. 192.

[32] O. Jahkola, "The role of ICT tools and contextual factors in global virtual teams," School of Science2013, Aalto University.

[33] J. H. E. Andriessen, Working with Groupware - Understanding and Evaluating Collaboration Technology, London: Springer-Verlag London Limited, 2003.

[34] M. Vlachopoulou and V. Manthou, "Partnership alliances in virtual markets," International Journal of Physical Distribution \& Logistics Management, 2003, vol. 33, no. 3, pp. 254-267.

[35] M. Chesher, R. Kaura, and P. Linton, Electronic Business and Commerce, London: Springer, 2003.

[36] H. Afsarmanesh et al., "Collaborative networks and their breeding environments, IFIP TC5 WG 5.5," presented at Sixth IFIP Working Conference on Virtual Enterprises, 2005, Valencia, Spain.

[37] L. M. Camarinha-Matos, "Collaborative networks in the internet of services," presented at 13th Ifip Wg 5.5 Working Conference on Virtual Enterprises, 2012, Bournemouth, UK.

[38] P. Ratnasingham and K. Kumar, "Trading partner trust in electronic commerce participation," presented at 21st International Conference on Information Systems, 2000

[39] M. Kollberg and H. Dreyer, "Exploring the impact of ICT on integration in supply chain control: A research model," Department of Production and Quality Engineering, Norwegian University of Science and Technology, Norway, 2006.

[40] S. R. Hiltz, J. J. Gonzalez, and M. Turoff, "ICT support and the effectiveness of decision making in disasters : A preliminary system dynamics model," presented at the 10th International ISCRAM Conference 2013, Baden-Baden, Germany.

[41] G. DeSantic, M. S. Poole, and G. W. Dickson, "Interpretive analysis of team use of group technologies," Journal of Computing, 1993, vol. 3 , no. 1, pp. 1-30.

[42] J. W. Palmer, "Supporting the virtual organization through Information technology in a new venture: The RETEX experience," presented at the ACM SIGPR/SIGMIS Special Interest Group Annual Conference on Computer Personnel Research, 1996.

[43] W. Li, Y. Badr, and F. Biennier, "Digital ecosystems: Challenges and prospects," presented at the International Conference on Management of Emergent Digital EcoSystems2012, ACM: Addis Ababa, Ethiopia, pp. $117-122$.

[44] J. Joo, "A business model and its development strategies for electronic tourism markets," Information Systems Management, 2002, pp. 59-69.
[45] M. Rowe, J. Burn, and E. Walker, "Small and medium enterprises clustering and collaborative commerce - A social issues perspective," Ballarat, Australia.

[46] N. A. C. Mat, Y. Cheung, and H. Scheepers, "Determining partner selection criteria using information communication technology (ICT) tools," presented at the 25th Australasian Conference on Information Systems, Auckland, New Zealand, 2014.

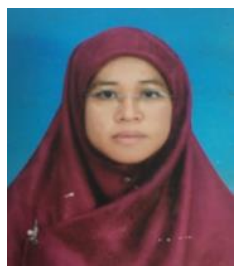

Noor Azliza Che Mat is currently a lecturer at Schoo of Informatics and Applied Mathematics, Universiti Malaysia Terengganu. She received her master degree in computer science from Universiti Kebangsaan Malaysia, Malaysia in 2001. Her research interests are in multimedia and decision support system.

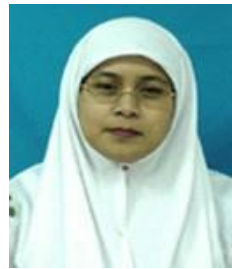

Noor Maizura Mohamad Noor is an associate professor at School of Informatics and Applied Mathematics, Universiti Malaysia Terengganu. Her recent research work focuses on improving organizational decision making practices through the use of technologies. This includes research interests in the design, development and evaluation of decision support systems for analyzing and improving decision processes. Her research interests also focus on the areas of computer science, intelligent decision support system, clinical decision support system, and information system as well as action research in education. She has presented and published over two hundreds of research papers on the decision support system at various international and local refereed journals, conferences, seminars and symposiums.

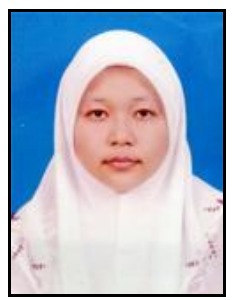

Rosmayati Mohemad is currently a senior lecturer a School of Informatics and Applied Mathematics, Universiti Malaysia Terengganu (UMT). She received her $\mathrm{PhD}$ degree in Computer Science from Universiti Kebangsaan Malaysia, Malaysia in 2013. Her research interests are in knowledge engineering and decision support system and currently focusing on modelling ontology for supporting decision-making process in special education and forensics domain. She is an editor of books, conference proceedings and also reviewer of international journal and conference papers. She is a member of IEEE. 